\title{
Analisa Hidrograf Satuan Sintetik Nakayasu Dan ITB Pada Sub DAS Konto, Jawa Timur
}

\author{
Nastasia F. Margini, Danayanti A. D. Nusantara, M. Bagus Ansori \\ Institut Teknologi Sepuluh Nopember \\ e-mail : nastasia@ce.its.ac.id
}

\begin{abstract}
Abstrak - Perhitungan debit banjir rencana merupakan suatu bagian yang sangat penting dalam merencanakan bangunan air. Dengan perencanaan debit banjir yang tepat dan sesuai akan menyebabkan pembangunan sarana prasarana keairan menjadi efektif dan efisien serta dapat mengurangi resiko akan kegagalan bangunan akibat bencana alam seperti banjir. Selain pemilihan periode ulang rencana yang tepat sesuai dengan resiko yang akan dihadapi oleh suatu bangunan keairan, dalam perhitungan debit banjir rencana juga diperlukan metode yang tepat untuk dapat menggambarkan hidrograf yang sesuai dengan karakteristik suatu daerah aliran sungai (DAS) dimana suatu bangunan keairan tersebut akan dibangun.

Sub DAS Konto, salah satu anak Sungai Brantas, yang merupakan sungai besar dan penting di Jawa Timur. Sehingga keberadaan debit airnya juga sangat menentukan kebermanfaatannya untuk kehidupan masyarakat sekitar. Didalam penelitian akan menggunakan metode Nakayasu dan ITB yang dibandingkan dengan hasil pengukuran debit di lapangan.

Kata Kunci : hidrograf sintetik, Nakayasu, ITB, Sub Sub DAS Konto, Sungai Brantas
\end{abstract}

\section{PENDAHULUAN}

Perhitungan debit banjir rencana dalam merencanakan dimensi suatu bangunan air merupakan suatu bagian yang sangat penting. Dengan perencanaan debit banjir yang tepat dan sesuai akan menyebabkan pembangunan sarana prasarana keairan menjadi efektif dan efisien. Selain keektifannya yang didapat hal itu mampu mengurangi resiko akan kegagalan bangunan akibat bencana alam seperti banjir. Perhitungan debit banjir rencana diperlukan untuk dapat menggambarkan hidrograf yang sesuai dengan karakteristik suatu daerah aliran sungai (DAS) dimana suatu bangunan keairan tersebut akan dibangun.

Sub Sub DAS Konto sebagai lokasi studi, merupakan salah satu anak Sungai Brantas, sungai besar di Jawa Timur. Sehingga keberadaan debit airnya juga sangat menentukan kebermanfaatannya untuk kehidupan masyarakat sekitar. Dengan adanya perubahan tata guna lahan yang sangat besar, jumlah debit air pada Sungai Konto juga mengalami fluktuatif khususnya debit banjir dan bangunan pengendali banjir.

Pendekatan model yang tepat dan sesuai dengan karakteristik suatu DAS akan memberikan dampak yang hampir menyerupai besar debit sebenarnya. Terdapat beberapa metoda hidrograf satuan sintetesis yang dikembangkan seperti cara Nakayasu, Snyder-Alexeyev, SCS, GAMA-1, ITB, ITS-1 dan yang terbaru ITS-2 (Tunas, 2015). Kesemua metode tersebut sangat populer dan umum digunakan di Indonesia.
Hanya saja saat membuat model tersebut harus dilakukan penyesuaian atau pengkalibrasian dalam menghitung debit puncak dan bentuk hidrograf banjir dengan data sebenarnya. Seperti halnya Hidrograf Nakayasu (asli dan belum dimofikasi) yang telah sering digunakan di Indonesi terkadang masih jauh dari hidrograf satuan observasi, Indra Agus. (2007).

Penelitian ini menggunakan data DAS dari Sub DAS Konto yang kemudian dibuatlah model hidrograf satuan menggunakan Nakayasu dan ITB.

\section{DASAR TEORI}

Hidrograf merupakan penggambaran secara grafik mengenai hubungan besaran debit dan waktu. Hidrograf sendiri merupakan respon dari hujan yang terjadi pada suatu wilayah. Karena sebab itulah untuk masing-masing wilayah atau DAS memiliki bentuk hidrograf yang berbeda tergantung kondisi DAS dan karakteristiknya.

Hidrograf memiliki tiga bagian yang penting, yaitu : bagian naik, bagian puncak, dan bagian turun seperti pada gambar 1 . 


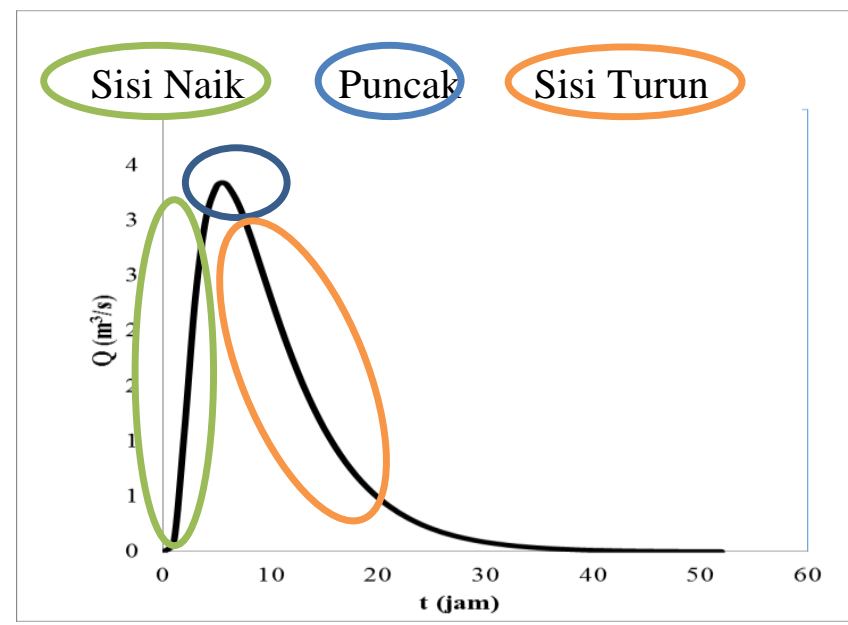

Gambar 1. Contoh bentuk grafik hidrograf

Hidrograf satuan merupakan penggambaran hujan efektif yang diubah menjadi limpasan langsung di outlet pengeluaran catchment area. Untuk setiap DAS memiliki hidrograf satuan yang berbeda tergantung karakteristiknya. Begitu juga untuk hidrograf satuan sintetik umumnya diturunkan dari karakteristik suatu DAS yang khas dan unik, seperti halnya HSS Nakayasu dan HSS ITB yang akan digunakan dalam perhitungan penelitian ini.

\section{Hidrograf Satuan Sintetik Nakayasu}

Hidrograf Nakayasu dikembangkan di Jepang dan sangat populer di Indonesia. Perhitungan debit banjir rancangan untuk suatu bangunan air di Indonesia umumnya menggunakan metode Nakayasu yang ditambah dengan metode lain sebagai pembandingnya. Persamaan umum Hidrograf Satuan Sintetik Nakayasu adalah sebagai berikut:

$$
\begin{aligned}
& \mathrm{Qp}=\mathrm{C} . \mathrm{A} \cdot \mathrm{R} 03,6(0,3 \mathrm{Tp}+\mathrm{T} 0,3) \\
& \mathrm{Tp}=\operatorname{tg}+0,8 \mathrm{tr} \\
& \operatorname{tg}=0,21 \times \mathrm{L} 0,7 \quad(\mathrm{~L}<15 \mathrm{~km}) \\
& \operatorname{tg}=0,4+0,058 \times \mathrm{L}(\mathrm{L}>15 \mathrm{~km}) \\
& \mathrm{T} 0,3=\alpha \times \operatorname{tg} \\
& \mathrm{R} 0 \text { = hujan satuan }(\mathrm{mm}) \text {, } \\
& \mathrm{A}=\text { luas DAS }\left(\mathrm{km}^{2}\right) \text {, } \\
& \mathrm{Tp}=\text { Waktu sampai puncak banjir (jam), }
\end{aligned}
$$

$$
\begin{aligned}
& \operatorname{tr}=\text { satuan waktu hujan, } \\
& \alpha=\text { parameter hidrograf, } \\
& \mathrm{L}=\text { panjang sungai }(\mathrm{m}) .
\end{aligned}
$$

Berikutnya adalah rumusan yang digunakan dalam menggambarkan hidrograf Nakayasu Asli antara lain:

a. Pada saat kurva naik, $0 \leq \mathrm{t} \leq \mathrm{Tp}$, maka

$$
Q t=Q p\left(\frac{t}{T p}\right)^{2,4}
$$

b. Pada kurva turun, $\mathrm{Tp}<\mathrm{t} \leq(\mathrm{T} p+\mathrm{T} 0,3)$, maka

$$
Q t=Q p \times 0,3^{\frac{t-T p}{T 0,2}}
$$

untuk $(\mathrm{Tp}+\mathrm{T} 0,3) \leq \mathrm{t} \leq(\mathrm{Tp}+\mathrm{T} 0,3+$ 1,5T0,3), maka

$$
Q t=Q p \times 0,3^{\frac{(t-T p)+(0,5 T 0,3)}{1,5 T 0,3}}
$$

dan untuk $\mathrm{t}>(\mathrm{Tp}+\mathrm{T} 0,3+1,5 \mathrm{~T} 0,3)$, maka

$$
Q t=Q p \times 0,3^{\frac{(t-T p)+(1,5 T 0,3)}{2 T 0,3}}
$$

Didalam penelitian ini juga dibuatlah perhitungan menggunakan Nakayasu modifikasi 2 (Qoriaulfa, 2016) dengan rumusan yang berbeda dari segi koefisiennya saja, antara lain :

a. $\operatorname{tg}=0,4+0,119 \times \mathrm{L} \quad$ (10)

b. Pada saat kurva naik, $0 \leq \mathrm{t} \leq \mathrm{Tp}$, maka

$$
Q t=Q p\left(\frac{t}{T p}\right)^{0,5}
$$

c. Pada kurva turun, $\mathrm{Tp}<\mathrm{t} \leq(\mathrm{Tp}+\mathrm{T} 0,3)$, maka

$$
\begin{aligned}
& Q t=Q p \times 0,3^{\frac{t-T p}{0,8 T 0,2}} \\
& \text { untuk }(\mathrm{Tp}+\mathrm{T} 0,3) \leq \mathrm{t} \leq(\mathrm{T} p \\
& 1,5 \mathrm{~T} 0,3), \text { maka } \\
& Q t=Q p \times 0,3^{\frac{(t-T p)+(0,5 T 0,3)}{0,5 T 0,3}}
\end{aligned}
$$

untuk $(\mathrm{Tp}+\mathrm{T} 0,3) \leq \mathrm{t} \leq(\mathrm{Tp}+\mathrm{T} 0,3+$

dan untuk $\mathrm{t}>(\mathrm{Tp}+\mathrm{T} 0,3+1,5 \mathrm{~T} 0,3)$, maka

$$
Q t=Q p \times 0,3^{\frac{(t-T p)+(1,5 T 0,3)}{6 T 0,3}}
$$

\section{Hidrograf Satuan Sintetik ITB}

Hidrograf ITB ini memiliki beberapa rumusan yang digunakan antara lain (Natakusumah,dkk. 2011) : 


$$
\begin{array}{ll}
T L=C t \times 0,21 L 0,7 & (\mathrm{~L}<15 \mathrm{~km}) \\
\mathrm{T}=C t \times 0.527+0,058 L & (\mathrm{~L}=15 \mathrm{~km})
\end{array}
$$

dengan :

$T L=$ Time Lag (jam)

$C t=$ Koefisien untuk proses kalibrasi

$L=$ Panjang sungai terpanjang $(\mathrm{km})$

Sedangkan pada bagian pembentukan kurva terdapat rumusan untuk bagian lengkung naik dan lengkung turun, yaitu :

1. Lengkung Naik

$$
q(t)=t^{a} \quad(0 \leq \mathrm{t} \leq 1)
$$

2. Lengkung Turun

$$
q(t)=\exp \left(1-t^{\beta \times C p}\right) \quad(\mathrm{t}>1 \mathrm{~s} / \mathrm{d} \infty)
$$

dengan :

$\mathrm{t}=(\mathrm{T} / \mathrm{Tp})$ adalah waktu yang telah dinormalkan (detik)

$\mathrm{q}=(\mathrm{Q} / \mathrm{Qp})$ adalah debit yang telah dinormalkan $\left(\mathrm{m}^{3}\right)$

Debit puncak hidrograf satuan sintetis akibat untuk hidrograf ITB ini, adalah sebagai berikut :

$Q p=\frac{R \times A_{D A S}}{3,6 T p \times A_{H S S}}$

dengan :

$Q p=$ Debit puncak hidrograf satuan (m3/detik)

$R=$ Curah hujan satuan $(\mathrm{mm})$

$T p=$ Waktu mencapai puncak (jam)

$A D A S=$ Luas DAS $(\mathrm{km} 2)$

$A H S S=$ Luas kurva satuan hidrograf tak

berdimensi

\section{METODOLOGI}

Metologi yang dilakukan dalam penelitian paper ini terbagi atas 3 tahap, antara lain :

a. Pengumpulan data sekunder.

Data yang dikumpulkan untuk penelitian ini meliputi :

- Data DAS baik itu tata guna lahan, luas DAS,dll

- Data hujan dari 2 stasiun, yaitu stasiun Badas dan Wangkal Kepuh

- Data debit pengukuran pada Stasiun AWLR (Automatic Water Level Record) Brodot, yang setiap data tersebut kami dapatkan dari BBWS (Balai Besar Wilayah Sungai) Brantas. b. Melakukan analisis data, antara lain :

- Menghitung hujan rata-rata wilayah dengan menggunakan Aritmatic method dikarenakan hanya terdapat 2 stasiun yang berpengaruh terhadap Sub DAS Konto yaitu Badas dan Wangkal Kepuh.

- Menghitung hujan efektif

- Melakukan perhitungan HSS Nakayasu, dan ITB pada lokasi studi

c. Pengujian keandalan dari 2 metode dengan melakukan kalibrasi dengan data terukur.

Bagan alir penelitian selengkapnya dapat dilihat pada Gambar 1 berikut ini :

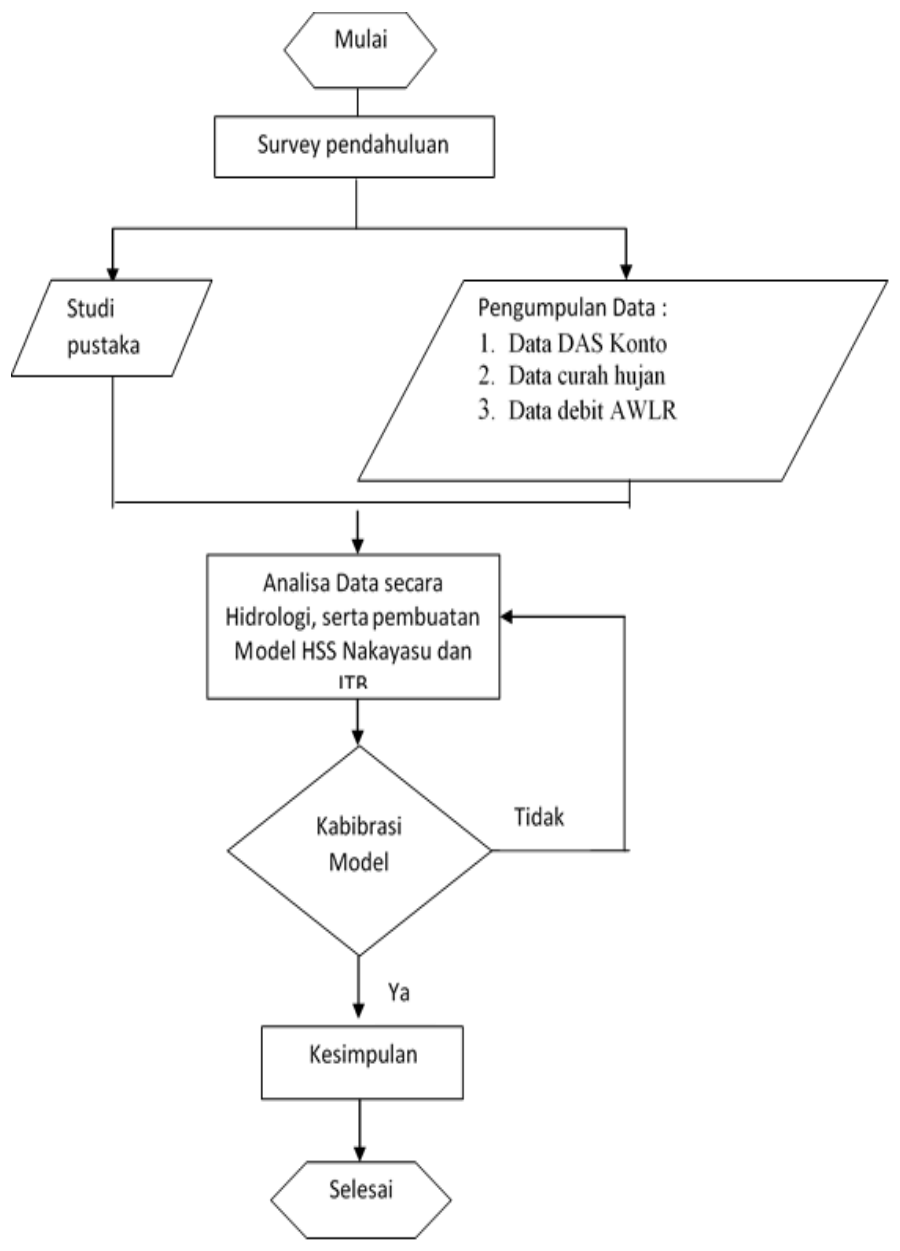

Gambar 1. Diagram Alir Peneitian

\section{PEMBAHASAN}

Sub Sub DAS Konto merupakan salah satu sub DAS di DAS Brantas, Jawa Timur. Sungai Konto merupakan bagian dari sistem DAS Brantas yng memiliki luas $568 \mathrm{~km}^{2}$ dengan panjang keseluruhan jaringan sungai Sub DAS Konto yaitu $168,34 \mathrm{Km}$. 
Sub DAS Konto memiliki dua stasiun hujan yang berpengaruh, yaitu : Badas dan Wangkal Kepuh serta stasiun pengukur debit air Brodot. Data yang didapatkan mulai tahun 2014-2017 baik data hujan maupun debitnya. Data tersebutlah yang kemudian digunakan dalam perhitungan hujan efektif hingga hidrograf satuan data terukur maupun hidrograf satuan sintetis. Untuk data terukur seperti pada tabel 1 dan gambar 2 dibawah ini :

Tabel 1. Hidrograf Satuan dari Data Terukur

\begin{tabular}{|c|c|c|c|}
\hline t (jam) & $\begin{array}{c}\text { HS Observasi } \\
(\mathbf{m 3 / d e t}) / \mathbf{m m}\end{array}$ & $\mathbf{t}(\mathbf{j a m})$ & $\begin{array}{c}\text { HS Observasi } \\
(\mathbf{m 3} / \mathbf{d e t}) / \mathbf{m m}\end{array}$ \\
\hline 0,0 & 0,00 & 4,8 & 1,90 \\
\hline 0,3 & 0,03 & 5,3 & 1,50 \\
\hline 0,6 & 0,07 & 5,8 & 1,30 \\
\hline 0,8 & 0,10 & 6,3 & 1,02 \\
\hline 1,0 & 1,06 & 7,3 & 0,99 \\
\hline 1,3 & 1,70 & 8,0 & 0,80 \\
\hline 1,6 & 2,30 & 8,7 & 0,60 \\
\hline 1,9 & 2,80 & 9,4 & 0,54 \\
\hline 2,2 & 3,10 & 10,0 & 0,40 \\
\hline 2,8 & 3,50 & 10,7 & 0,35 \\
\hline 3,3 & 2,90 & 11,4 & 0,23 \\
\hline 3,8 & 2,40 & 12,1 & 0,22 \\
\hline 4,3 & 2,25 & 12,7 & 0,20 \\
\hline
\end{tabular}

Sumber : Data Perhitungan

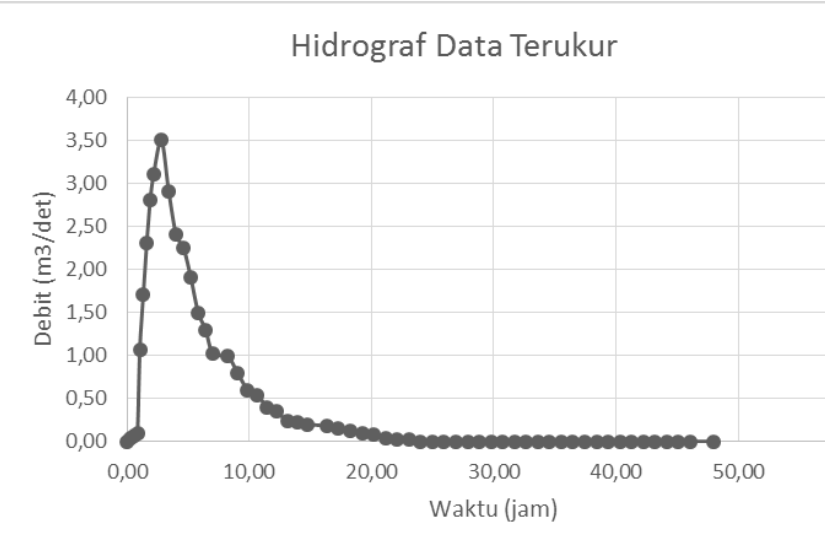

Sumber : Data Perhitungan

Gambar 2. Grafik Hidrograf Limpasan Langsung untuk Data Terukur

Langkah selanjutnya adalah menghitung hidrograf satuan untuk Nakayasu dan ITB. Pada saat perhitungan menggunakan Nakayasu menggunana rumusan asli dan juga rumusan Nakayasu Modifikasi 2 (Qoriaulfa, 2016). Dari hasil kedua rumusan kemudian didapatkan hasil bahwa debit puncak antara Nakayasu asli dan Nakayasu modifikasi 2 lebih mendekati kondisi lapangan pada Nakayasu Modifikasi 2. Namun untuk waktu puncak hasilnya sama.

Kedua metode Nakayasu tersebut diperoleh dengan menggunakan $\alpha=3$ yang berarti naik dengan cepat dan turun secara lambat seperti kondisi lapangan limpasan langsungnya. Hasilnya ditunjukkan pada gambar 3 dibawah ini :

Perbandingan HSS Nakayasu dan Data Terukur

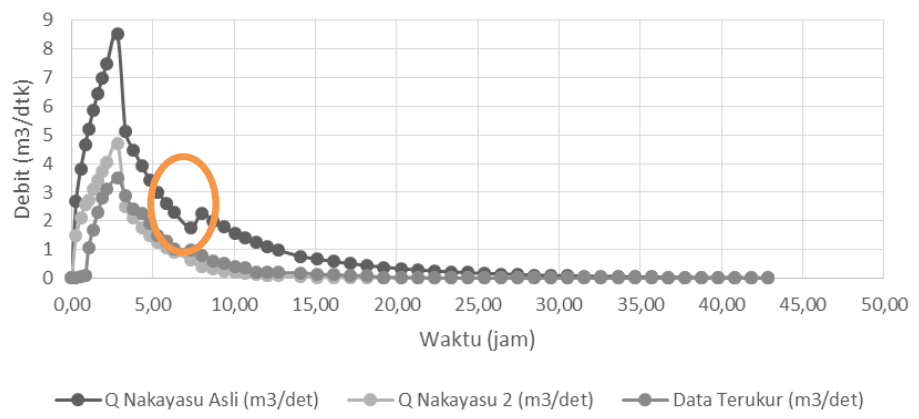

Sumber : Perhitungan

Gambar 3. Grafik Hidrograf Nakayasu Asli, Nakayasu Modifikasi 2, dan Data Terukur

Terdapat sedikit penyimpangan pada bagian Hidrograf Nakayasu Asli, pada saat nilai debit seharusnya nilai turun kemudian menjadi naik lagi pada waktu antara jam ke 5 dan 10 dan kemudian turun dengan $\mathrm{Q}$ mendekati 0 hingga time base.

Sebagai perbandingan kemudian dibuat perhitungan dengan menggunakan Rumusan ITB dengan data yang sama yaitu dari Sub DAS Konto. Hasil grafiknya dapat dilihat pada Gambar 4.

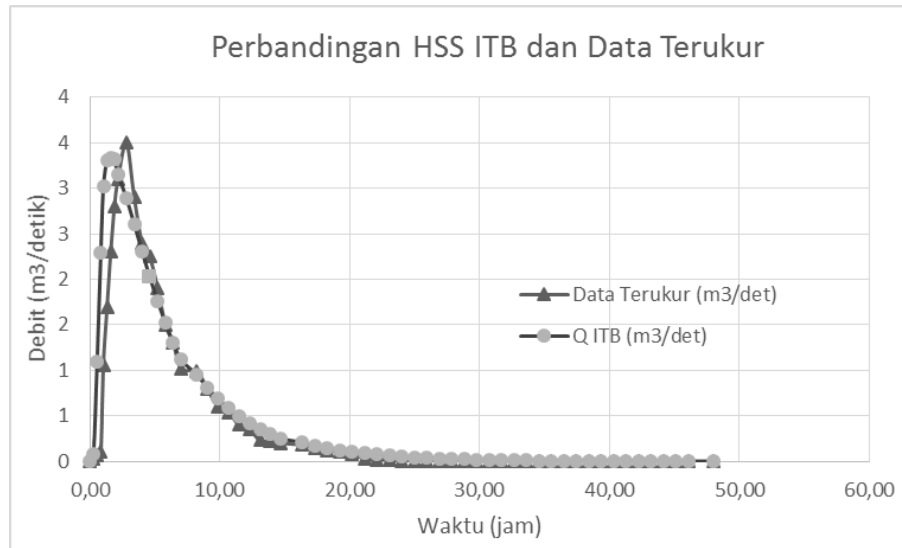

Sumber : Perhitungan

Gambar 4. Grafik Hidrograf ITB dan Data Terukur

Dari penggambaran hirograf data terukur dan Metode ITB memiliki bentuk yang hampir sama 
serta debit banjir dan waktu puncak yang mendekati kondosi aslinya.

Dari ketiga metode perhitungan baik Nakayasu Asli, Nakayasu modifikasi 2 dan ITB hasilnya dibandingkan dengan menggunakan data terukur. Untuk hasil debit puncak dan waktu puncak tersedia dalam tabel 2, untuk grafiknya tersedia pada gambar 5 di bawah ini :

Tabel 2. Perbandingan Hasil Perhitungan Debit Puncak dan Waktu Puncak

\begin{tabular}{|l|c|c|c|c|}
\hline & $\begin{array}{c}\text { Data } \\
\text { Terukur }\end{array}$ & $\begin{array}{c}\text { Nakayasu } \\
\text { Asli }\end{array}$ & $\begin{array}{c}\text { Nakayasu } \\
\text { Modifikasi 2 }\end{array}$ & ITB \\
\hline Qp (m3/detik) & 3,50 & 8,52 & 4,69 & 3,34 \\
\hline Tp (jam) & 2,8 & 2,8 & 2,8 & 1,6 \\
\hline
\end{tabular}

Sumber : Perhitungan

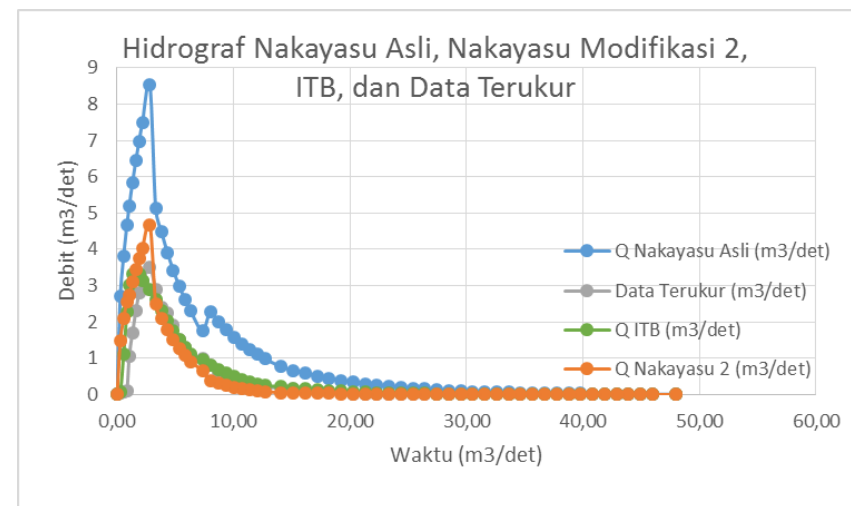

Sumber : Perhitungan

Gambar 5. Grafik Hidrograf Nakayasu Asli, Nakayasu Modifikasi 2, ITB dan Data Terukur

Hasil ketiga hidrograf satuan yang telah dikalibrasi dan dibandingkan dengan data terukur di Sub DAS Konto masih belum ada yang sesuai secara keseluruhan dari debit puncaknya maupun waktu puncaknya. Akan tetapi, apabila dilihat per bagian, misal waktu puncaknya saja, debit puncknya saja, ataukah bentuk hidrografnya masing-masing memiliki kedekatan yang hampir mendekati. Untuk itu perlu dilakukan adanya modifikasi untuk hidrograf satuan sintetik yang akan digunakan pada Sub DAS Konto.

\section{KESIMPULAN}

Penelitian menggunakan dua metode ini, yaitu Nakayasu dan ITB pada Sub DAS Konto dapat 'disimpulkan bahwa :

1. Hasil pemodelan Nakayasu Asli dan Nakayasu Modifikasi 2, Nakayasu Modifikasi 2 lebih menunjukkan nilai Qp dan Tp yang mendekati data pengamatan.

2. Dari Nakayasu modifikasi 2 dengan ITB dan data terukur, hasil dari debit puncak ITB lebih mendekati debit terukur. Sedangkan bila dilihat dari segi waktu puncak yang lebih mendekati adalah metode Nakayasu baik Nakayasu Asli maupun Nakayasu Moifikasi 2.

3. Dari setiap metode hidrograf yang telah ada, perlu adanya modifikasi untuk setiap DAS karena bersifat unik dari setiap perbedaan karakteristiknya.

\section{DAFTAR PUSTAKA}

[1] Agus, I. 2007. Modifikasi Persamaan Hidrograf Satuan Sintetis Metoda Nakayasu Terhadap Hidrograf Satuan Observasi DAS Ciliwung Hulu. Rekayasa Sipil.

[2] Anwar, Nadjadji., Umboro Lasminto, I Gede Tunas. 2018. Hidrograf Satuan Sintetik ITS2.Surabaya : ITS Press.

[3] Arsyad, S. 2012. Konservasi Tanah dan Air.Bogor : IPB Press

[4] Asdak, C. 2002. Hidrologi dan Pengolahan Aliran Sungai. Jakarta: Gajah Mada University Press.

[5] Natakusumah, D. K. 2011. Prosedur Umum Perhitungan Hidrograf Satuan Sintetis dengan Cara ITB dan Beberapa Contoh Penerapannya. Jurnal Teknik Sipil.

[6] Nugroho, Sutopo Purwo. 2001. Analisis Hidrograf Satuan Sintetik Metode Snyder, Clark Dan Scs dengan Menggunakan Model Hec-1 di Das Ciliwung Hulu Jurnal Saint \& Teknologi Modifikasi Cuaca.

[7] Ponce, V. M. 1989. Engineering Hydrology: Principles And Practices. Englawoods Cliffs New Jersey: Practice Hall.

[8] Qoriaulfa, Agreista Vidyna,dkk. 2016. Analisis Limpasan Langsung menggunakan Nakayasu, SCS dan ITB Studi Kasus Sub DAS Progo Hulu. Prosising SNTT FGDT.

[9] Triatmodjo, B. 2013. Hidrologi Terapan. Yogyakarta: Beta Offset.

[10] Tunas, I.G., Nadjadji Anwar, Umboro Lasminto. (2015a), Kinerja HSS Snyder, Nakayasu, dan GAMA I Pada DAS terukur di Sulawesi Tengah, Jurnal Teknik Sumber Daya Air, vol. 1 no. 2 Juni 2015 Himpunan Ahli Teknik Hidraulika Indonesia (HATHI). Hal 105-114

[11] Wang, Q. J., The genetic algorithm and its application to calibrating conceptual rainfallrunoff models, Water Resour. Res., 27(9), 24672471, !991. 